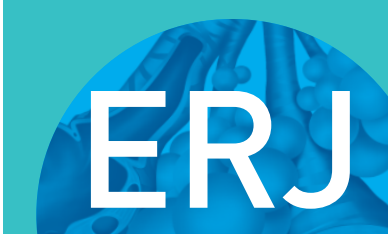

open research

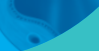

\title{
Everyday life experiences of spouses of patients who suffer from pulmonary arterial hypertension or chronic thromboembolic pulmonary hypertension
}

\author{
Bodil Ivarsson (10 ${ }^{1,2}$, Trygve Sjöberg ${ }^{1,2}$, Roger Hesselstrand ${ }^{2,3}$, \\ Göran Rådegran ${ }^{2,4}$ and Barbro Kjellström ${ }^{5}$
}

Affiliations: 'Dept of Cardiothoracic Surgery, Skåne University Hospital, Lund, Sweden. ${ }^{2}$ Clinical Sciences Lund, Lund University, Lund, Sweden. ${ }^{3}$ Dept of Rheumatology, Skåne University Hospital, Lund, Sweden. ${ }^{4}$ Section for Heart Failure and Valvular Disease, Skåne University Hospital, Lund. ${ }^{5}$ Cardiology Unit, Dept of Medicine, Karolinska Institutet, Stockholm, Sweden.

Correspondence: Bodil Ivarsson, Dept of Cardiothoracic Surgery/THAI, Skåne University Hospital, Klinikgatan 11, 22185 Lund, Sweden. E-mail: bodil.ivarssonamed.lu.se

\section{ABSTRACT}

Introduction: Spouses play a crucial role, both physically and psychologically, for patients with pulmonary arterial hypertension (PAH) and chronic thromboembolic pulmonary hypertension (CTEPH). Our aim was to investigate the spouse's experiences when living with a partner diagnosed with PAH or CTEPH.

Methods: We used a qualitative interview study design based on open-ended questions analysed using qualitative content analysis.

Results: 14 spouses were interviewed. Two categories that describe spouses' experiences of dealing with everyday life were identified: "Living in an insecure life situation" and "Providing and receiving information and support". The experiences reported by the spouses were that their life situation was insecure, and that they had challenges in providing and receiving information and support. Most spouses also wanted and felt a need to be more involved in the care.

Conclusion: The spouses were only partly satisfied with their life situation. To support the spouse's participation, the PAH/CTEPH team should encourage the patient to bring their spouse along, and offer them the opportunity to participate in the contacts with healthcare and provide information on an individual family perspective.

@ERSpublications

Spouses of PAH and CTEPH patients have challenges in providing and receiving information. The experiences reported by them are that their life situation is insecure. They request that PAH and CTEPH centres involve relatives to a greater extent. http://ow.ly/Y1N130nrNU9

Cite this article as: Ivarsson B, Sjöberg T, Hesselstrand R, et al. Everyday life experiences of spouses of patients who suffer from pulmonary arterial hypertension or chronic thromboembolic pulmonary hypertension. ERJ Open Res 2019; 5: 00218-2018 [https://doi.org/10.1183/23120541.00218-2018].

Received: Nov 182018 | Accepted after revision: Jan 082019

Copyright $\odot E R S$ 2019. This article is open access and distributed under the terms of the Creative Commons Attribution Non-Commercial Licence 4.0. 


\section{Introduction}

Chronic illnesses such as pulmonary arterial hypertension (PAH) and chronic thromboembolic pulmonary hypertension (CTEPH) incur a life-changing experience for the patients and their families, where spouses often take on a large responsibility [1]. The diseases can affect daily activities and quality of life negatively, taking both physical and psychological aspects into account [2]. However, advances in treatment strategies [3] have improved the survival as well as the quality of life, and an increased feeling of hope and optimism can be sensed among these patients [4].

When a chronic illness is diagnosed, the patient's family often becomes the primary source of practical and emotional support [5-7]. The role as an informal caregiver can affect the family member's ability to work and have a negative impact on the financial situation [1,8]. Interest and possibility of sexual activities might decrease and for women, pregnancy might no longer be an option $[1,9,10]$. For some, home assistance may be considered a burden and an intrusion in life [10].

Sharing the life of someone with a chronic illness, e.g. PAH or CTEPH, may mean having to cope with the loss of freedom and the struggle to handle life $[10,11]$. Therefore, the aim of this study was to investigate the spouse's experiences when living with a partner diagnosed with PAH or CTEPH.

\section{Methods}

This study used a qualitative descriptive design with interviews of 14 spouses living with a partner diagnosed with PAH or CTEPH. First, a letter with information about the study was sent to 14 patients, selected from a PAH/CTEPH expert clinic at Skåne University Hospital (Lund, Sweden), followed by a telephone call. All patients agreed to participate, and their spouses were informed and asked to consent so that the study leader could contact them. The spouse was then provided with oral and written information about the study, and written consent was obtained after acceptance.

The investigation conformed to the principles outlined in the Declaration of Helsinki. The Regional Ethical Board in Lund approved the study (LU 2011/364).

\section{Interviews}

All interviews (interview guide in table 1), conducted as a dialogue in Swedish between the first author (B.I.) and the spouse, lasted between 13 and $58 \mathrm{~min}$. To secure the content and quality of the interview, the first interview served as a pilot test. The interview guide was deemed satisfactory and was used in the study. Five interviews were conducted in person and nine by telephone. All interviews were audio-taped and transcribed verbatim.

\section{Data analysis}

Transcripts from interviews resulted in 71 double-spaced pages of text and were analysed using Microsoft Word functions [13] by means of qualitative content analyses inspired by GRANEHEIM and LundMAN [14]. To become familiar with the text, one author (B.I.) read the interviews repeatedly. Significant "meaning units" were identified, condensed and coded. The codes were then convened in subcategories and abstracted into categories. Another author (T.S.) independently and critically examined the subcategories and categories, and reflected on them. In a critical and open dialogue between the two authors, and after ensuring accuracy in all steps, the final analysis was performed to confirm the content and reach consensus so as to strengthen the credibility of the results [14]. To improve the validity of the subcategories and to illustrate the spouses' experiences, direct quotations (translated into English) are presented in the text. The names of patients and spouses have been anonymised as "NN" and "SP", respectively.

\section{TABLE 1 Interview guide}

Opening question

Follow-up questions
Tell me your experiences of living with a partner who had been diagnosed with PAH or CTEPH?

Please tell more about your experiences associated with:

- Participation (relationship, involvement)

- Information (communication)

- Support (practical, emotional, informational, network)

Probing questions were also asked for clarification and to continue the conversation

Based on guidelines from the Swedish Board of Health and Welfare [12]. 


\begin{tabular}{lc}
\hline TABLE 2 Demographic characteristics of the spouses & 14 \\
Subjects & $5 / 9$ \\
Women/men & $68(40-87)$ \\
Age years & 1 \\
Level of education & 8 \\
$\quad$ Elementary school & 5 \\
$\quad$ High school & 7 \\
$\quad$ College/university & 4 \\
Employed/retired & 4 \\
Families with children aged $\leqslant 18$ years & \\
\hline Data are presented as n or median (range). & \\
\hline
\end{tabular}

\section{Result}

A total of 14 spouses participated in the study: five women and nine men. Their median age was 68 years. Their partners (patients) had lived with the PAH or CTEPH diagnosis for 1-14 years. Demographic and clinical characteristics of the spouses are shown in table 2. Two main categories and 12 subcategories were identified (table 3).

\section{Living in an insecure life situation}

Diverted feelings when detecting severe illness

Most spouses were shocked, but also relieved, when their partners were diagnosed. Often they had lived with their partner before and during the search for help for their symptoms, and underwent investigations and the experience of not being taken seriously. Establishing the diagnosis was often associated with a feeling that their partner had already deteriorated.

NN underwent many investigations to find out what the disease was. It took quite a while. They [the physicians] did not come to any conclusion ... it was a time of uncertainty, you really wanted an answer. (SP1)

\section{Pharmaceutical benefits and concerns}

The spouses were aware that the future was unpredictable, but still had expectations about the medical treatment and its development. Some expressed concerns that the treatment would become ineffective or that the side-effects made their partners not take their medicines as they should. The spouses also questioned how they could be more supportive and help their partners with regard to medication adherence.

She is on some kind of treatment ... I think she ignores it sometimes as she does not want to feel ill. (SP2)

\section{The need for unspoken information}

Patients would be reluctant to talk about the disease, even positive feelings like stability and improvement, maybe because it reminds them of the illness. Thus, spouses would like to be able discuss the disease with

\section{TABLE 3 Summary of categories and subcategories}

$\begin{array}{ll}\text { Categories } & \text { Subcategories } \\ \text { Living in an insecure life situation } & \text { Diverted feelings when detecting severe illness } \\ & \text { Pharmaceutical benefits and concerns } \\ \text { The need for unspoken information } \\ \text { Handling being a parent } \\ \text { Common social life } \\ \text { The disease impact on the economy } \\ \text { Providing and receiving information and support } & \text { Awareness and assessment of information } \\ & \text { Convey information } \\ & \text { Concerns about disease knowledge } \\ & \text { Supplying practical and emotional support } \\ & \text { Finding support and strength } \\ & \text { Peer support }\end{array}$


the healthcare staff, such as issues that might occur, the patients' own contacts with healthcare and appropriate activities, including sex life for their partner. This was described as an insurmountable obstacle to overcome, partly due to concerns about going behind the back of their partner and partly due to the confidentiality rules in the healthcare system.

To protect me, NN might not even want to tell me the truth, and then it would be good to get information from another source. (SP12)

\section{Handling being a parent}

Those with young or adult children had concerns about the hereditability of the disease, although some children had been genetically tested. Those with children still living at home said they sometimes had to take more responsibility for the children, but pointed out that this was not a burden. Concerns were expressed as to how much the children understood and were affected by having a parent with a chronic and fatal illness.

It was kind of a shock, I stood there with children .... Children do understand what we say ... and probably understood that NN might die. (SP12)

\section{Common social life}

Some spouses described that thanks to medication and/or an understanding surrounding, their partners could participate in activities and their social life was not affected. Others described a gradual decrease in their social life along with disease progression and that they had adapted to their partner's abilities (e.g. hiking and golfing as they did earlier, sometimes with others, was no longer practical). Usually, the spouses did not describe it as a burden.

Guests are invited daytime as NN sleeps a lot. Before, we used to travel together with others, but now, even a tiny uphill walk is no longer possible. (SP10)

The disease impact on the economy

Some spouses felt that the family economy was affected by the disease due to unpaid leave and travel expenses related to healthcare visits. They felt life had become more limited and money was no longer used for pleasure. Others mentioned they had to make changes professionally to be able to participate and give support to their partner, with a negative effect on the family economy.

Of course it has affected the economy; I have had to hire more people [to the family business]. (SP5)

\section{Providing and receiving information and support}

Awareness and assessment of information

Most spouses said the primary source of information about the disease was their partner. They did not feel invited in by the healthcare professionals to participate and when this happened, they felt that the healthcare staff took it for granted that they had already received some degree of information. The spouses obtained most of their information from disease-specific brochures dispensed by their partner and some that they found in the waiting room of the PAH/CTEPH expert clinic.

Information and communication around PAH and CTEPH found on the internet and social media were important for many spouses. At the same time, they raised concerns about trusting the information they found and that some information was old, incomprehensible or scary.

All information about this disease I have found by myself on the internet, in this PAH forum. I have also signed up on a network on Facebook ... there is a need to connect with others with the same family situation as us, that includes kids. (SP8)

\section{Convey information}

The majority of the spouses said that the responsibility to convey information about their partner's illness to their children and relatives fell on their shoulders. Therefore, they felt they wanted to be more involved in their partner's healthcare contact. When they informed their managers, co-workers and others about the disease, they were usually met with great understanding about their life situation.

I have told them [colleagues] everything, what it mean and all ... do not know how they perceive what it is like [the disease]. I take time off ... we are a small company, so we are tight. (SP11) 
Concerns about disease knowledge

Being the spouse of a patient with a severe and rare disease raised concerns about healthcare and ongoing research. The spouses noticed that while knowledge about PAH and CTEPH was high at the PAH/CTEPH expert clinic, it was lacking and posed a problem when their partner needed to seek care or help in other parts of the healthcare system. The spouses had high hopes for research and wished for a cure for the disease to be close by.

As no one knows where PAH comes from, why not take in all data from everybody with PAH [in the world] and study what they have in common in their daily lives? You will get good statistics and then you can exclude some reasons or add up the extremes (SP12)

\section{Supplying practical and emotional support}

The spouses struggled on how to achieve a balance between their partners' independence and being overprotective. The degree of physical support the spouse needed to provide depended largely on their partner's symptoms, which could fluctuate from day to day. In terms of daily life, some spouses said that they had taken over more and more of the heavy household work. For some, this was supplemented with municipal assistance such as housekeeping, disability aids and parking permits. Others said that they did the same amount of household and gardening work as before, and when the patient participated, they did it at their own rate.

Giving emotional support was considered as difficult by most of the spouses as their partners did not easily speak of their illness, feelings or mood.

$N N$ is like, if you do not talk about it [the disease], it does not exist. (SP8)

\section{Finding support and strength}

The spouses perceived that they had friends and family around them with whom they could vent their feelings, but at the same time they felt it could be difficult for others to understand how it really is to live with a person with a chronic and fatal illness. Most spouses expressed that it was important to have something meaningful to take part in beyond the disease. The main activities were work, associations, volunteering, a hobby or seeking spiritual support. In these surroundings, the spouses felt they met people who understood their situation, but mostly they felt they had found a place where they could be part of everyday life. Few spouses had been offered professional counselling from the healthcare system.

My personal time is very limited. But, I will take on some voluntary work for associations, because on top of this [NN disease] I have a large need to take care of myself. (SP14)

\section{Peer support}

The awareness of disease-specific associations and support on social media, in open or closed groups, was mixed among spouses. Some participated in patient association meetings with the patient, and experienced the contact with others in the same situation and the lectures as very positive. In contrast, others tried to get involved but experienced that it was hard to meet, hear or read about others whose disease worsened or was fatal.

Someone had started an internet group ... but it all came back to when I believed there was no hope ... and then I stopped reading. (SP12)

\section{Discussion}

The main experiences reported by spouses of patients diagnosed with PAH or CTEPH were that their life situation was insecure, and that they had challenges in providing and receiving information and support. Spouses also wanted and needed to be more involved in the care already from the time of diagnosis. They said that they were the recipients of a range of emotions from their partners, such as shock, anxiety, fear, insecurity and anger, and that these emotions sometimes went all the way back to the time when the patient fell ill but did not receive a correct diagnosis or adequate care.

When couples talked about the experience of living with a chronic disease, they seem to handle their current health situation better than couples who did not talk about it [15]. In the present study, the spouses expressed frustration that they rarely received complete information about the disease and its treatment from neither their partner nor the PAH/CTEPH expert clinic. Similar results have been presented previously, where spouses of patients with $\mathrm{PAH}$ wanted to participate in the care process but found it hard to get involved [16]. Due to integrity issues, it will always be the patient who is called to the $\mathrm{PAH} / \mathrm{CTEPH}$ expert clinic. Thus, the importance of the PAH/CTEPH team to encourage the patient to 
bring their spouse along, and to take the initiative to interact with the spouse and offer them the opportunity to participate in the contacts with healthcare, should be encouraged.

It is understandable that the spouse, e.g. the healthy parent, in this study showed concerns for their children's wellbeing. Children who live with a parent with a chronic illness tend to direct their feelings inside more than other children [17] and thus it is important to acknowledge their needs. It is recommended that families seek support from professionals and from peers, both inside and outside the family [17]. The spouses in this study had overwhelmingly positive attitudes, despite having to take on large responsibilities for the household and other physically heavy tasks. This also included those with smaller children who said it was no burden to take on extra activities with the children when needed. However, spouses might not always be able to be the main support for their partner. They need to work, participate in a child's activity, or they might be suffering from disease or disability themselves. The PAH/ CTEPH team must pay attention to the whole family situation and be wary of additional needs of assistance from society that might be required.

Chronic illness is connected to costs such as hospitalisations, treatment side-effects and medications [18]. Despite the Swedish healthcare system covering almost all costs related to the care of patients, some spouses still claimed that the disease had a negative impact on the family economy. This mostly included taking unpaid leave to accompany their partner to the hospital, adjustments to living quarters and special tools to allow activities. In addition to their partner's failing health, financial strain was also mentioned as a reason why relationships with friends had changed. The costs the disease incurs, and its impact on the whole family, are probably largely unknown to the general public. The feeling of social isolation this might incur has been previously described in a European study where a third of carers felt a lack of understanding from their social environment and thereby some degree of isolation [1].

If the relatives have a key role in patient support, they are often proactive, sometimes more than the patient, in obtaining facts, advice and support from a variety of sources such as literature, the internet or patient associations [19]. This is in line with the findings in the present study where most spouses felt that they had to take on the responsibility themselves to find the information they needed. They often searched for information online and visited chat forums even though they were sceptical of certain information. While the spouses saw themselves as part of a team, their partners could be unwilling to talk about the emotional and relational consequences of their illness, a frustrating feeling for the spouse. Consequently, it is understandable and advisable for the spouse to seek support outside the closest family. For example, patient associations, which often include relatives, can be a valuable resource and provide educational and emotional support $[1,19]$. The $\mathrm{PAH}$ team should be encouraged to provide a package, containing information about the disease, who to contact, and links to content-reviewed internet sites and existing patient/relative associations, which they hand out to spouses and others in close contact with the patient.

Although every spouse who participated in this study wanted to play a part in their partner's illness and everyday life, they also said that their private time was very important. This implies time where they can be by themselves and gather strength. In families who live with a chronic illness, it is important to maintain the family's wellbeing in everyday life [20]. To do this, routines should be established so that time can be spent on what is highly valued, and thereby create positive feelings and thoughts [20]. It can be assumed that if the spouse feels secure with regard to the disease, e.g. well informed and with access to support, it will affect both their life and their relationship with their partner positively.

\section{Strengths and limitations}

The study is a qualitative single-centre study of spouses and generalisation to a larger population cannot be made. The partners of the interviewed spouses were purposely selected to include a wide span of age, time since diagnosis and family situation, allowing a large variation. The achieved variation and the limited number of patients do not allow analyses related to these factors. However, the variation can support a general sense of spouses' reality and experiences, and thus may provide a good understanding of the interaction between spouses, healthcare professionals and patients.

\section{Conclusion}

Spouses of patients with PAH or CTEPH experienced that they were only partly satisfied with participation, information and support. To help spouses, the PAH/CTEPH team must establish a close relationship with them and involve them when giving information and support, based on a family perspective applicable to the patient's individual situation. 
Conflict of interest: None declared.

Support statement: This study was supported by unrestricted research grants from Actelion Pharmaceuticals Sverige AB The sponsor did not have any role in study design, data collection, analysis or interpretation of data, nor in writing the manuscript or the decision to submit the paper for publication. Funding information for this article has been deposited with the Crossref Funder Registry.

\section{References}

1 Guillevin L, Armstrong I, Aldrighetti R, et al. Understanding the impact of pulmonary arterial hypertension on patients' and carers' lives. Eur Respir Rev 2013; 22: 535-542.

2 Galiè N, Humbert M, Vachiery J-L, et al. 2015 ESC/ERS Guidelines for the diagnosis and treatment of pulmonary hypertension: the Joint Task Force for the Diagnosis and Treatment of Pulmonary Hypertension of the European Society of Cardiology (ESC) and the European Respiratory Society (ERS): endorsed by: Association for European Paediatric and Congenital Cardiology (AEPC), International Society for Heart and Lung Transplantation (ISHLT). Eur Respir J 2015; 46: 903-975.

3 McLaughlin VV, Shah SJ, Souza R, et al. Management of pulmonary arterial hypertension. J Am Coll Cardiol 2015; 65: 1976-1997.

4 Cole E, Armstrong I, Cutts K. Links between psychological factors and health-related quality of life in pulmonary hypertension. Eur Respir J 2016; 48: PA1622.

5 Ivarsson B, Ekmehag B, Hesselstrand R, et al. Perceptions of received information, social support, and coping in patients with pulmonary arterial hypertension or chronic thromboembolic pulmonary hypertension. Clin Med Insights Circ Respir Pulm Med 2014; 8: 21-28.

6 Ivarsson B, Ekmehag B, Sjoberg T. Support experienced by patients living with pulmonary arterial hypertension and chronic thromboembolic pulmonary hypertension. Heart Lung Circ 2016; 25: 35-40.

7 Kingman $\mathrm{M}$, Hinzmann $\mathrm{B}$, Sweet $\mathrm{O}$, et al. Living with pulmonary hypertension: unique insights from an international ethnographic study. BMJ Open 2014; 4: e004735.

8 Hwang B, Howie-Esquivel J, Fleischmann KE, et al. Family caregiving in pulmonary arterial hypertension. Heart Lung 2012; 41: 26-34.

9 Ivarsson B, Ekmehag B, Sjoberg T. Information experiences and needs in patients with pulmonary arterial hypertension or chronic thromboembolic pulmonary hypertension. Nurs Res Pract 2014; 2014: 704094.

10 Wryobeck JM, Lippo G, McLaughlin V, et al. Psychosocial aspects of pulmonary hypertension: a review. Psychosomatics 2007; 48: 467-475.

11 Lichenstein S, McDonough A, Matura LA. Cyber support: describing concerns of caregivers of people with pulmonary hypertension. Comput Inform Nurs 2013; 31: 581-588.

12 Swedish Board of Health and Welfare. Din skyldighet att informera och göra patienten delaktig - handbok för vårdgivare, verksamhetschefer och personal. [Your obligation to inform and involve the patient - handbook for caregivers, heads of departments and staff.] 2015. www.socialstyrelsen.se/publikationer2015/2015-4-10 Date last accessed: December 4, 2018.

13 La Pelle N. Simplifying qualitative data analysis using general purpose software tools. Field Methods 2004; 16 85-108.

14 Graneheim UH, Lundman B. Qualitative content analysis in nursing research: concepts, procedures and measures to achieve trustworthiness. Nurse Educ Today 2004; 24: 105-112.

15 Checton MG, Greene K, Magsamen-Conrad K, et al. Patients' and partners' perspectives of chronic illness and its management. Fam Syst Health 2012; 30: 114.

16 Alami S, Cottin V, Mouthon L, et al. Patients', relatives', and practitioners' views of pulmonary arterial hypertension: a qualitative study. Presse Med 2016; 45: e11-e27.

17 Sieh DS, Visser-Meily JMA, Oort FJ, et al. Risk factors for problem behavior in adolescents of parents with a chronic medical condition. Eur Child Adolesc Psychiatry 2012; 21: 459-471.

18 Dufour R, Pruett J, Hu N, et al. Healthcare resource utilization and costs for patients with pulmonary arterial hypertension: real-world documentation of functional class. J Med Econ 2017; 20: 1178-1186.

19 Graarup J, Ferrari P, Howard LS. Patient engagement and self-management in pulmonary arterial hypertension. Eur Respir Rev 2016; 25: 399-407.

20 Ziegert K. Maintaining families' well-being in everyday life. Int J Qual Stud Health Well-being 2011; 6: 7206. 